\title{
The levels of Community Involvement in Health (CIH): a case of rural and urban communities in KwaZulu-Natal
}

\author{
GG Mchunu, PhD \\ University of KwaZulu-Natal, School of Nursing
}

\section{Kev words}

Community involvement in health, ladder of participation, Primary health care, and health programmes

\section{Correspondence address}

\section{Dr Gugu Mchunu}

University of Kwa Zulu -Natal,

School of Nursing,

Desmond Clarence Building,

$4^{\text {th }}$ Floor, Room 416,

Durban, 4041

Tel : (031) 2601075

Fax : (031) 2601543

E-mail: mchunug@ukzn.ac.za

\begin{abstract}
Curationis 32 (1): 4-13
The study aimed to describe the practice of community involvement in health programmes. The study therefore explored the nature and practice of community involvement in health programmes in the two communities in KwaZulu Natal. The study was guided by the conceptual framework adapted from Arnstein's, (1969) Ladder of Citizen Participation. This framework shows different levels and steps in community participation. A case study method was used to conduct the study. The two cases were one urban based and one rural based community health centers in the Ilembe health district, in Kwa Zulu Natal. A sample of 31 persons participated in the study. The sample comprised 8 registered nurses, 2 enrolled nurses 13 community members and 8 community health workers. Data was collected using structured individual interviews and focus group interviews, and was guided by the case protocol. Community involvement in health largely depended on the type of community, with rural community members being in charge of their health projects and urban community members helping each other as neighbours in times of need.
\end{abstract}

\section{Background}

Community involvement in health $(\mathrm{CIH})$ plays an important role in rendering primary health care (PHC) services to the community. According to the World Heath Organization (WHO) (1978:51), community involvement can take many forms, including assessment of the situation, definition of problems and setting of priorities. The community can then help to plan PHC activities and can co-operate fully when these activities have been carried out. This approach emphasizes that, in PHC collaborations, residents and health providers need to work in partnership as they each have their area and level of expertise. In this partnership, it is argued, health professionals and community constituents will share responsibilities, decision making and commitment to interventions and outcomes to improve the community's health
(Porsche, 2004: 147)

The basic characteristics of the concept of community participation are that

- participation must be active,

- people must have the right and responsibility to exercise power over decisions that affect their lives, and

- $\quad$ there must be mechanisms available to allow the implementation of the decisions made by the community (Dennill, King \& Swanepoel, 2002:82; Laverack, 2007:26).

Without these characteristics in the delivery of health care, the health professionals cannot claim the involvement of the community in their implementation of health programmes.

It has been widely reported that communities are seldom involved in the 
development of health programmes beyond "being expected to bring their children for immunizations and passively to accept a thin offering of services" (Brown, Holtby, Zahnd \& Abbott 2005: 2 ; WHO, 1988: 28). This means that although the importance of community involvement in health services is widely expounded, the actual involvement is less apparent At this stage, community involvement is viewed as the key to success in the delivery of health care, yet there seems to be very little or no actual community involvement in the community context. Though in the Alma Ata conference community involvement in health was identified as one of the principles in PHC practice, thirty ycars post this conference there is still a missing link between the community and health care system, with community members being mere recipients of the health care and not involved in the decision making and planning of health programmes (Bukenya 2008:1; Brown, Holtby, Zahnd \& Abbott 2005: 2).

In keeping in line with this concept of community involvement, the South African government introduced the following initiatives:

1. The government's National Health Act (Act No. 61 of 2003) which is based on the belief that every individual has the right to achieve optimal health. Furthermore, community participation is identified as an essential element that the national health system (NHS) must develop at a local level in order to be fully effective and not as an entity that can be prescribed and legislated into bcing (Republic of South Africa, 2004: 22).

\section{In the white paper for Transforma-} tion of the Health System in South Africa (Department of Health, 1997) the objectives for restructuring the health system were set. One of these objectives was to foster community participation across the health sector by involving communities in various aspects of the planning and provision of health services (Department of health, 1997).

A review of relevant literature reveals that very few studies have been done on community participation in Kwa Zulu Natal (KZN). The findings of the national primary health facilities survey conducted by Viljoen, Heunis, Janse van Rensburg, van Rensburg, Engelbrecht, Fourie, Steyn, and Matebesi, (2000:82) showed that little progress had been made in facilitating community participation in PHC in South Africa since 1998. A study conducted in KwaZulu Natal exploring community understanding of $\mathrm{CIH}$ revealed that community members in both urban and rural communities have a common understanding of $\mathrm{CIH}$ being a collaborative effort between health professionals and community members (Mchunu \& Gwele, 2005: 35). Even though $\mathrm{KZN}$ is among the provinces where headway had been made, the change in terms of the practice of community involvement in health has been described as very slight.

\section{Rationale for the importance of community involvement in health}

As the key concept in primary health care, community involvement is said to be within the level of community residents' participation in health decisionmaking. It is argued that the residents need to participate in decisions about the health of the community in order to promote development and self- reliance. Community participation in health programmes generates a sense that health and decision-making is community-owned, and the personal experiences of citizens become integral to the formulation of policy (Wright, Parry \& Mathers J, 2005:58). There is an emphasis that in PHC, community members and health providers need to work in partnership as they each have their area and level of expertise. This, it is argued, is needed to actively engage community members as active participants in solving complex community problems (Porche, 2004: 147)

Bhuyan (2004: 2) and Stanhope and Lancaster (2004: 350) are in agreement with Porche's argument that community involvement is a critical element of PHC and health development. But, there is a further argument that the people's involvement should not just be in the support and functioning of health services but more importantly, in the definition of health priorities and the allocation of scarce health resources at the district level. Nkasa and Chapman (2006: 512) have advocated that involving community members in planning project activities will ensure sustainability of community projects. For these authors, a community project will be sustained if those involved in it come to feel ownership of it.

The achievement of an appropriate health care delivery system requires involvement of people at grass root as part of the process so that they can effectively utilize the service (Dolamo, 2009: 5). Literature has shown that communities invest in their community resources in a number of diverse ways to achieve community development. However, previous research studies have revealed that while community involvement in health services is widely expounded, the actual involvement in health programmes is still surrounded by a host of challenges including lack of leadership, lack of credibility and the fact that many people still need to be convinced of the dividends of their involvement (Padarath et al., 2006:101).

\section{Problem statement}

In spite of all the initiatives by the South African government to improve health care delivery at primary health care level, some problems persist, including the lack of optimal community involvement. Several questions remain unanswered, particularly questions aiming to explore the nature and practice of community involvement in health programmes.

\section{The purpose and objectives of the study}

The study aimed to describe the practice of community involvement in health related community programmes, using a ladder of participation as a framework. The objectives of the study were therefore to

Describe the levels of $\mathrm{CIH}$ in rural and urban communities.
- Determine similarities and dif ferences between the rural and urban practice of CIH.

\section{Conceptual framework}

The study was guided by the model adapted from the Ladder of Citizen Participation (Arnstein, 1969) (Figure 1)

This framework was chosen because it showed all the different levels and steps in community participation. In this study, the ladder's steps represented 
Figure 1: The ladder of participation (adapted from Arnstein (1969) in International Save the Children Alliance, 1997: 443)

\section{THE LADDER OF \\ PARTICIPATION}

In health services.......

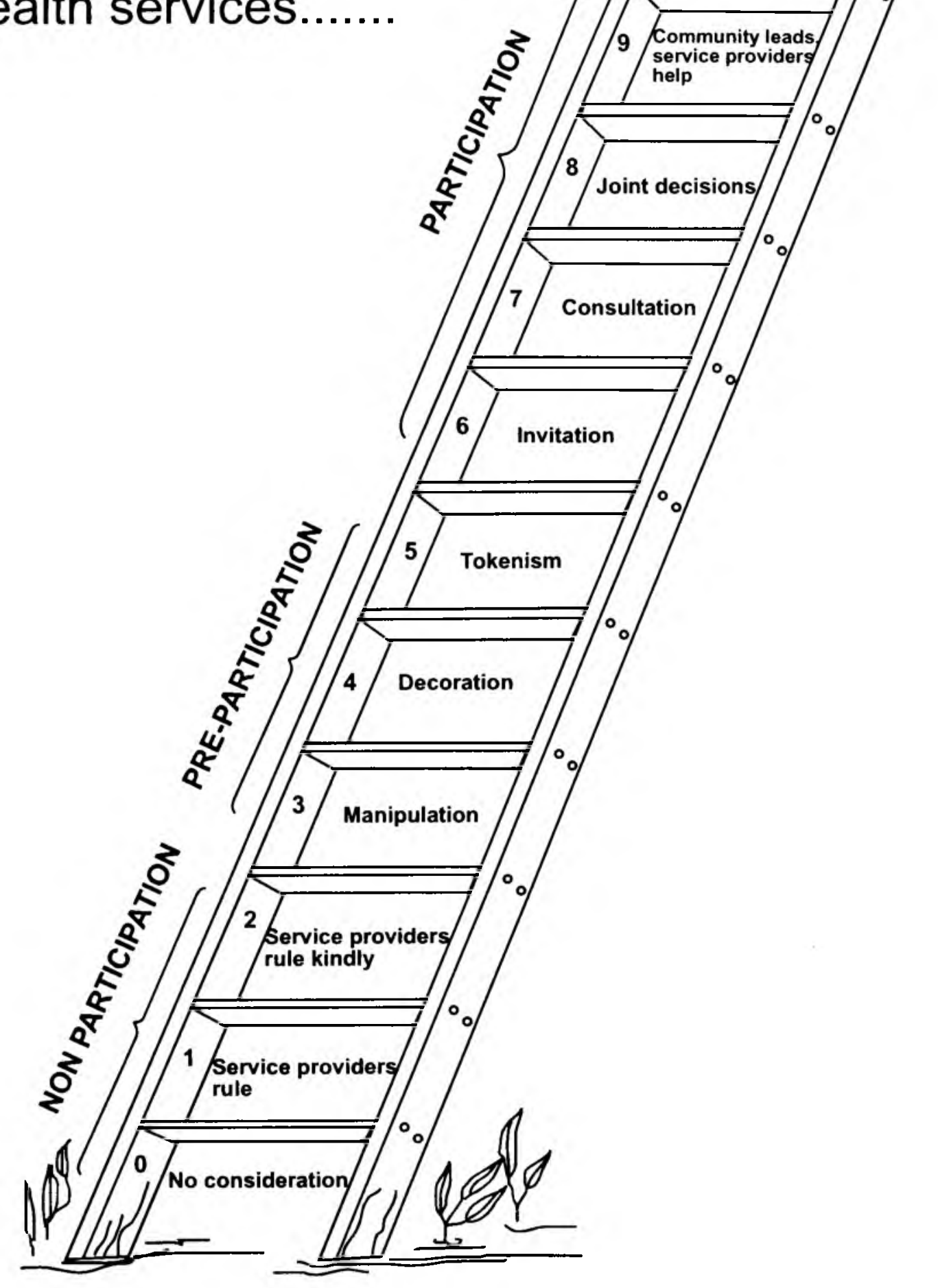


the level of community participation in each community involved.

In this Ladder of citizen participation levels of community participation are explained as follows:

\section{Participation}

\section{Community in charge}

The community decides what to do. The health professionals are involved only if the community asks for help.

9 The community leads/the health professionals help

The community takes the lead in deciding, with help from the health professionals.

8 Joint decision

The health professionals and the community decide together on a basis of equality.

7 Consultation

The health professionals consult the community and consider their opinion carefully, then the health professionals decide, taking all opinions into account.

6 Invitation

The health professionals invite the community's ideas but make the decision themselves on their own terms.

\section{Pre-participation}

5 Tokenism

The health professionals decide what to do. Afterwards the community is allowed to decide some minor aspects.

\section{Decoration}

The health professionals decide what to do, the community takes part by singing, dancing or performing ceremonial functions.

\section{Manipulation}

The health professionals decide what to do and ask the community members if they agree (the community must agree).

\section{Non-participation}

\section{The health professionals rule} kindly

The health professionals make all decisions, the community is told nothing except what they must do and they are given reasons and explanations.

The health professionals make all decisions; the community is told nothing except what they must do.

0

\section{No consideration for the} community

The community is not given any help or consideration at all, they are ignored.

\section{Definition of terms}

Community: It is a group of people who share some type of bond, who interact with each other, and who function collectively regarding common concerns. The bond may take many forms, in that it can be shared ethnicity or culture or living in a specific geographic location or it can take the form of similar interests, goals, or occupations (Clark, 2003). In addition to this definition the ANC's definition of the term community will be adopted, that is, "to represent those people living in the geographical area served by a community health centre" (ANC, 1994:61).

Community involvement and/or participation: This refers to a shift in emphasis from external agencies supplying health services, to the people of a community becoming active participants in their own health care. Community members become partners in health care by generating their own ideas, assessing their needs, involvement in decision-making process, planning, implementing, and even evaluating the care they receive. (Dennill et al. $2002: 9$ ). These two terms will be used interchangeably.

PHC communities: For this study, it means the people who are involved in the operation of the phenomenon, that is, the health professionals working in the health care centre and the community served by the health centre.

Health professionals: the members of the health team, including the nurses (all categories) working in community health centres.

Rural community: Geographically, this term refers to areas that are remote and isolated. Rural communities are not homogeneous, but the following characteristics for rural communities will be assumed, namely, (a) sparse populations, (b) low family income, (c) unemployment, (d) poor schools, and (e) inadequate to non existent health care systems (Deloughery, 1991).

Urban community: In this study it will refer to communities situated in the inner city, in which a large number of people live and work in close proximity. The assumption will be based on Mann's (1983) definition that in urban communities relationships are impersonal and superficial and segmental. Also, that the population is more heterogeneous due to greater mobility of the people.

\section{Literature survey}

In the literature review, the following key concepts were explored:

(a) the community, (b) primary health care (PHC), and (c) community involvement (participation). Relevant research articles on community participation in health problems and on measuring community participation were reviewed.

The WHO defines PHC, as:

"Essential care based on practical. scientifically sound and socially acceptable methods and technology made universally accessible to individuals and families through their full participation and at a cost that the community and the country can afford to maintain at every stage of their development in the spirit of self reliance and self determination" (WHO, 1978, p.16).

According to the WHO (1978), primary health care policies need to be transferred into practical programmes. It is further asserted that there is a need for a specific strategy for formulation and implementation of these primary health care programmes. The national strategy plan will include, among other things:

- Support from relevant component from other sectors, such as education, transport, agriculture, and sectors dealing with environment.

- Commitment of the government to develop and launch the strategy and to maintain momentum.

- In order to devise and implement the strategy, the communities in need of such care should be identified, in order to decide on their grouping for the purpose of support and their referral.

- $\quad$ For communities to be involved in their health development they need to have easy access to the 
right kind of information concerning their health situation and how they themselves can improve it. This information can be in the form of magazines, newspapers, radio, television, films, plays, posters, commu nity notice boards and any other means available, including the health professionals, so as to increase the accessibility of the services. The assumption is that the more accessible the services are, the more interested people will be to participate in health programmes.

Elaborating on these basic strategies, Dennill et al. (2002) asserted that Community participation and involvement refers to a shift in the emphasis from external agencies supplying the health services, to the people of a community becoming active participants in their own health care.

They become partners in health care by generating their own ideas, assessing their needs, making decisions, planning, implementing, and even evaluating the care they receive. This process encourages and allows the community to take responsibility for their own situation, thus empowering them. It also encourages self-reliance and self- determination (Dennill et al., 2002:9).

According to Reid (2000) there is no one right way define community involvement and as community participation will look different in every community. Yet, according to this author, there are some common elements to sound participation that will be found in all communities. Some authors therefore provide traditional definition of community involvement in health, in terms of partnerships, achieving the goals and objectives of health programmes, and community taking responsibility for their own health (WHO, 2006, Rifkin 1990, Bhuyan 2004).

Pragmatic definitions of community involvement in heath view this concept as in terms of decision making and empowerment such that it is an empowerment tool through which the communities take responsibility to solve their own health and development problems (Morgan, 2001, Abelson, 2001).

\section{Research methodology}

\section{Research design:}

A qualitative research approach using the case study design was chosen for this study. A multiple case study design was used. The practice of community participation in rural and urban communities was explored and an analysis of the type of community participation was done based on the conceptual framework. The case study protocol was used to guide the researcher to keep her focused on the purpose of the study.

The case study design focuses on holistic descriptions and explanation, answering the questions such as "how" and "what" (Yin, 2003:7). Within the context of this study this involved the assessment of how the community members were involved in the development of health programmes, including identification of needs, and planning and decision-making in the implementation of these programmes. The study looked at the practice of community participation in both urban and rural communities in the Ilembe health district, province of KZN.

\section{Setting}

The setting was community health centres and their surrounding communities in different types of communities. The sub-districts within Ilembe district (formerly Region F) were chosen as suitable sites for this study because the district ranges between extreme urban and extreme rural communities. One clinic was chosen from each sub-district.

\section{Case study protocol}

According to Yin (2003: 67) a case study protocol is essential if one is doing a multiple case study. This case study protocol contained the instrument as well as procedures and general rules to be followed in using the protocol (Yin, 2003:67).

The case protocol contained the following information:

- Short description of each case, in terms of its demography, services offered and present activities.

- Data collection strategies Questions that were asked: "How have you participated in health projects in the past two years?", "In your view, what health activities involve community members in this community?" Probing was done during the interview process

\section{Case Description}

In this study the case was a health centre (clinics) in the chosen health sub districts with all the community members utilising the clinic, health programmes and community health workers as its embedded units of analysis. The context of the case was the chosen urban (case A) and rural (case B) communities within the Ethekwini health district

\section{Case selection}

Cases were purposively selected to ensure that the chosen cases were typical of the population required (Gerring, 2007:147). One case was selected from each sub district to represent the rural community and the second case was selected to represent the urban community. Case A was an urban community while case $B$ was a rural community.

\section{Sample selection}

Theoretical sampling was used to select study participants. The initial group of participants were nurses and community members in different PHC communities. The researcher kept on including another group of participants other than the nurses and the community members as the need arose. In theoretical sampling, the researcher can do 'ongoing inclusion of groups' and 'selection of comparison groups' which can be done when the researcher needs to turn to certain groups or sub-groups for the next data collection (Glaser \& Strauss, 1967: 49, Polit \& Beck, 2004: 307).

A total of 31 participants representing both cases, participated in this study. In case A (urban community): All in all 17, participants were interviewed. These consisted of five registered nurses, six community members who live in the areas surrounding the town and six community health workers. Of the five interviewed registered nurses, three were in charge of the specific health programmes. These programmes were HIV/ AIDS, training of health personnel and CHWs coordination.

In case B (rural community), a total 
number of 14 participants were interviewed. The health professionals interviewed consisted of three registered nurses, one of whom was the person in charge of the clinic and two enrolled nurses. From the community side, interviewed were two izinduna, and five active community members. The community health workers included one community health workers' coordinator, who is in charge of the CHWs who are attached to the clinic, and one of the four volunteer community health workers who are not attached to the clinic.

In case $\mathrm{A}$, where active community members were not clearly identified, the researcher used convenience sampling to include community members. People who happened to be at the clinic at that time were identified as possible participants (Burns \& Grove, 2001 :374; Polit, Beck \& Hungler, 2001:237). The researcher visited the clinic over the period of one week and explained the proposed research to the clients who were waiting in the waiting area. The interested community members volunteered to participate, but could only be included if they were residents of this community and not just visiting.

In case B, community members were sampled using snowball sampling. This seemed to be the most appropriate method as the researcher was looking for people with specific traits (Polit \& Beck, 2004: 306), namely people who have been utilizing the same clinic for a number of years. The criterion for selecting active community members was through identification of these individuals by a variety of sources. These included the nursing staff, community health workers (such as the AIDS coordinators, the community health workers' trainers and facilitators). The researcher also included those community members identified by community leaders and other informants (such as Indunas and other respected community members).

\section{Data collection methods}

The strategies used for data collection included face-to-face interviews in the form of focus group interviews and individual interviews. The research questions were used in both the individual interviews and focus groups and the researcher had to probe to obtain more information.

Purposively selected focus group interviews were conducted where the informants were found as a group or for informants who were working together. This was to ensure that the groups were homogenous, and hence facilitate open discussion (Burns \& Grove, 2001: 452). One focus group was conducted in each community. In case A focus group was conducted with the community health workers whereas in case B the focus group was on community members. This was determined by the availability of participants.

\section{Data analysis}

Data collection and analysis were done simultaneously. The analysis of data was commenced by using a template, in this case the template being a case protocol. Template analytic techniques more open-ended and includes generation of themes, patterns and interrelationships in an interpretive rather than a statistical process (Crabtree \& Miller, 1992: 19). A case protocol together with the research question guided the analysis of data.

The researcher identified themes and patterns and did interpretational manual data analysis. Data was then segmented to meaningful units. The segments were coded and sorted into categories. Relationships among categories were then established. As described by Miles and Huberman, (1994: 90 ) within case and cross case analysis was done to compare the findings in different settings. Information was put in different arrays, a matrix of categories was developed and evidence placed within such categories (Miles \& Huberman: 1994 in Yin: 2003: 111). These were presented in tables.

\section{Trusworthiness}

To ensure richness and depth of data as well as to enhance credibility of this study, triangulation was implemented by utilizing multiple sources of data (Polit, Beck \& Hungler, 2001:313). For data triangulation multiple sources of data were used. This included using two cases, and having health professionals, community members and community health workers as study participants. For method triangulation, different methods of data collection were used and these included focus group interviews and individual interviews. Peer examination was achieved by discussing the findings with a colleague who is an experienced and credible researcher. Focus groups were also conducted for data verification and member checks.

\section{Ethical considerations}

Permission to conduct the study was requested from the department of health in KZN. Authorities from the different institutions concerned, namely, the various community health centres, were also approached for consent to conduct a study. Community leaders were also approached for their consent. All participants were asked for either a written or verbal informed consent or a choice to refuse to participate. They were informed that they were free to discontinue at any time of the study. To maintain confidentiality during interviews the researcher explained to the participants that whatever information was discussed during the interview should be kept in confidence. Furthermore, participants were asked not to give their real names, but to use pseudo names during the discussion. The researcher asked for permission to record all interviews including the focus groups. Participants were assured that no physical risks were involved in this study.

\section{Results}

Each case is presented individually using the case protocol, the research objectives and the conceptual framework. The levels of community involvement in health were derived from the participants' description of the practice of $\mathrm{CIH}$.

\section{Levels of community involvement in health in case A: urban community}

\section{Levels of $\mathrm{ClH}$}

In this community participants identified two types of community involvement in health namely (a) participation and (b) non-participation.

The community members and health professionals had differing views on the levels at which the members were involved in health.

Some community members verbalized 
that they sometimes met on their own to help each other should there be somebody who was ill in the community. The following quotes support this statement:

What we are doing is to meet and discuss if the person is sick. We advise him what to do or where to go if he has this problem.

We just help each other as neighbours and friends. Say if a person is sick we just plan and say let's go and see him.

The health professional were in agreement with this as they felt that there was a very high level of community participation since the community members identified some of their needs and acted upon them with some help from the health professionals. According to these health professionals wellestablished community structures had also been put in place by the community, with little help from health professionals.

Through these structures, the community could communicate with the clinic. From the interviews, the following quotes demonstrating this observation were identified:

My experience in CIH was the building of one of the clinics in which the community was involved right from the beginning. This clinic was built because the community identified the need...

The community has already chosen the community health workers; they have established the health committees and the clinic's involvement will only be in training the community health workers and supervision as and when needed.

Some participants in all categories disagreed that there was participation as they felt that they were still at non-participation level. The community members verbalized that although the staff was very friendly to them; they (health professionals) never went out to them, as the community and they are therefore never involved in decision-making. This was indicated in the following passages:

I've never been involved in any decision-making or changes being made at the clinic. time I visit the clinic is when I am sick. The sisters treat us very well but they don't go out to our community to discuss any health problems with us.

Some health professionals were in agreement with this non-participation, and they felt that the decisions came from the higher authorities, such as preplanned programmes on the health calendar. According to these health professionals, the clinic did not involve the community, as they should, in rendering health care services. These health professionals however felt that they did not have a stable community that they could involve in the health programmes. The following passages support these statements:

Sometimes the directors of clinic services and the community services work together with the local councils to make decisions. These decisions are then communicated to the community.

I don't see any community involvement in health programmes taking place in our clinic. In this clinic we deal mostly with people who visit the clinic because they work here in town, so I would be telling a lie if I say we ever go out to them for community development purposes.

The CHWs however described the level of community involvement as at participation level. These participants felt that the community was driving most of the community projects, and that they identified their own needs, and the health professionals assisted them to some extent.

The CHWs take responsibility to liase between the clinic and the community. We teach each other and the community about the existing health programmes.

Through community meetings we discuss any community problems. We talk to the community members and they identify the need for a project.

\section{Levels of $\mathrm{CHI}$ in case $\mathrm{B}$ : rural community}

From the community members, it emerged that all three levels of participation existed in this community as participants felt there was a) participa- tion, others identified the levels as (b) pre -participation while others believed that (c) non- participation existed in this community.

The community members felt that there was participation taking place but this involved only the community members and that the health professionals were not providing any form of support as far as these projects were concerned.

"We are nursing sick people at home; terminally ill people are at home without any support from the clinic. The clinic staff does not give us support such as gloves or to tell us how to give treatment to these sick people at home".

"We do have women's clubs such as handwork, gardening and candle making. Some of these projects were initiated by CHWs".

For the some community members there was some participation; however these participants felt that it was only at preparticipation level. These participants verbalized that they were only called during implementation of programmes when they were asked to come and give speeches and to dance.

This was viewed as "decoration" whereby health professionals decide what to do, the community takes part by singing, dancing or performing ceremonial functions.

Maybe it's during implementation when they go to dance at the clinic. People sometimes go to play sketches and sing at the clinic.

We are never involved in planning but we get informed if they want us to participate such as saying a poem, delivering a speech, and so on.

The health professional were in agreement with this community view on preparticipation level as they felt that sometimes, depending on the type of decision, the clinic staff made decisions, in which the community members would be involved during implementation, after being informed by clinic staff. According to these health professionals, the community is only involved during implementation of the health programmes.

They do attend the clinic functions and they participate by bringing their chil- 
Table 1: Cross Case analysis of Levels of $\mathrm{ClH}$

\begin{tabular}{|c|c|c|c|c|}
\hline Case & Level of Participation & Community & Health Professionals & CHWs \\
\hline \multirow[t]{3}{*}{ A } & Participation & Community in Charge & $\begin{array}{l}\text { Community leads, health } \\
\text { professionals help }\end{array}$ & $\begin{array}{l}\text { Community leads, health } \\
\text { professionals help }\end{array}$ \\
\hline & Pre-participation & & & \\
\hline & Non participation & $\begin{array}{l}\text { No consideration for } \\
\text { community }\end{array}$ & Professionals rule & $\begin{array}{l}\text { No consideration for } \\
\text { community }\end{array}$ \\
\hline \multirow[t]{3}{*}{ B } & Participation & Community in Charge & & $\begin{array}{l}\text { Community leads, health } \\
\text { professionals help }\end{array}$ \\
\hline & Pre-participation & Decoration & Decoration & \\
\hline & Non participation & $\begin{array}{l}\text { Health professionals rule } \\
\text { No consideration for the } \\
\text { community }\end{array}$ & $\begin{array}{l}\text { Health professionals rule } \\
\text { kindly }\end{array}$ & $\begin{array}{l}\text { No consideration for the } \\
\text { community }\end{array}$ \\
\hline
\end{tabular}

dren for competitions. Sometimes the school children participate by having drum majorettes and traditional dancing.

People like Mrs. X they give talks, they sing and dance we then do our bit on the health side, they tell people about the advantages of breastfeeding teaching them and we work very well together

They are already there; they get involved by having talks sketches, and participate if we have something at the clinic.

The other community members however agreed with some health professionals that there was no community participation at all. For these community members there were no projects that were in place and that involved the clinic and the community.

"We do not have any project that involves the community and the clinic. We are not involved in health matters at this point. I haven't heard of any project that involves the clinic and the community members at this stage maybe they just don't have anything in mind".

"Community involvement in health does not exist in this place, but we are also part of the problem since we do not have proper channels of communication such as health committees where we can report our health prob- lems".

The health professionals also made it evident that the decisions are made at the main clinic (sometimes based on clinic statistics) and they have to inform the community about these decisions which have to be implemented.

The CHWs in this community were divided into $\mathrm{CHWs}$ linked to the clinic and the volunteer CHWs. For CHWs linked to the clinic the feeling was that there was community involvement in health. They felt that the community was involved in decision making in all the health related matters. The involvement of the community was said to be from the planning to evaluation of the project. The following was quoted:

"We involve them at the beginning because they have to decide on the date. Before we do anything in our planning we have to let them know. So, it's from the beginning to the end. Even the program is compiled with them; we cannot do it alone because we are working with the community. We do not just come and tell them here is the programme".

The volunteer CHWs however had a different view as they felt that there was no community involvement in health programmes. The following lines were quoted:

"No, they do not encourage us to get involved. We would love to go and participate but they do not invite us, by the time we hear about an event at the clinic it's long past. This makes us feel bad because we are supposed to work with them; we are supposed to be there. We, the community have never been involved in the planning of these health events".

The results are summarized in table 1.

\section{Discussion and conclusion}

The rural community members felt that they were in charge of their health projects where they were working without the health professionals. This finding of the community being in charge of the projects is at the highest level in the ladder of participation, and therefore demonstrated a very high level of community participation in health programmes. The community projects which the community members were referring to included such projects as sewing, poultry farming and candle making only, which therefore excluded other health programmes such as immunisations, breastfeeding and health education.

The health professionals also felt that the community was involved in health programmes since they were involved during implementation of such health programmes as breastfeeding and immunizations. What also emerged from the rural community was that the two groups of CHWs were functioning in- 
dependently from each other, and there was therefore no integration in their service provision.

The findings in the urban community differed from that of the rural community in that community members in the urban community helped each other as neighbours in times of need without the help of the health workers. In the rural community the community was in charge by working on their own in their community projects. In the urban community, on the contrary, there were no community projects on which the community members were working.

This lack of interest in participation in health programmes by the urban community members confirms that the community cannot be defined in terms of its geographical boundaries and its shared interests. This is the case because the people in this community are in the same geographical boundary but they do not share the same interest with the other community residents in the same geographical boundaries as far as health needs are concerned. The urban community members did not identify the need to involve themselves in the clinic health programmes.

Community involvement in health, although it is usually externally introduced, should go beyond the level of welfare activities to ensure empowerment of the community.

The concept of $\mathrm{CIH}$ is a significant principle in the successful delivery of health care services. However, this term may be interpreted in different ways by different stakeholders. There is therefore a need for this concept to be redefined in different communities as there appears to be uncertainty in terms of its implementation to meet the goals of Alma Ata as stated by the WHO (1978)

\section{References}

ABELSON, J 2001: Understanding the role of contextual influences on local health-care decision making: case study results from Ontario, Canada. Social Science \& Medicine 53 (6), 777 793.

ARNSTEIN, SR 1969: A Ladder of Citizen Participation. JAIP.35 (4), 216-224.

BHUYAN, KK 2004: Health promo- tion through self-care and community participation: Elements of a proposed programme in the developing countries. BMC Public Health, 4:11 accessed on $027 / 02 / 2009$ via http:// www.biomedcentral.com/1471-2458/4/ 11.

BROWN, ER; HOLTBY, S; ZAHND, E \& ABBOTT, GB 2005: Communitybased Participatory Research in the California Health Interview Survey. Prev Chronic Dis. 2(4), 1-8

BUKENYA, D 2008: Community Partnering - the missing link. AMREF news

BURNS, N \& GROVE, SK 2001: The Practice of Nursing Research Conduct, Critique and Utilization (4th edition) Philadelphia: WB Saunders.

CLARK, MJ 2003: Community Health Nursing: Caring for Populations ( $4^{\text {th }}$ edition). USA: Prentice Hall

CRABTREE, BF \& MILLER, WL 1992: Doing qualitative research. Newbury: Sage.

DENNILL, K; KING, L \& SWANEPOEL, T 2002: Aspects of primary health care: community health in Southern Africa. South Africa: Oxford.

DEPARTMENT OF HEALTH 1997: White Paper for the Transformation of the Health system in South Africa. Government Notice No. 17910 , Pretoria. http://www.politv.org.za/govdocs/ white papers/health.html accessed on 23/02/2009

DOLAMO, BL 2009: Transforming Health Services Delivery: The Leadership Perspective Accessed on 25/02/ 2009 via http://www.denosa.org.za/ TRANSFORMING $\% 20$ THE $\% 20$ HEALTH \%20SERVICE\%20DELIVERY\%20II1.pdf

GERRING, J 2007: Case study Research: Principles \& Practices. USA: Cambridge University Press

GLASER, BG\& STRAUSS, AL 1967: The Discovery of grounded theory. New York: Aldine.

KAHSSAY, HM \& OAKLEY, P 1999:
Community involvement in health development: A review of the concept and practice. Geneva: WHO

LAVERACK, G 2007: Health Promotion Practice : Building Empowered Community. London: Open University Press

MCHUNU, GG \& GWELE, NS 2005: The meaning of community involvement in health: the perspective of primary health care communities, Curationis. 28(2), 30-37

MILES, MB \& HUBERMAN, AM 1994: Qualitative data analysis. Thousand Oaks: Sage.

MORGAN, LM 2001: Community participation in health: perpetual allure, persistent challenge. Health Policy Planning. 16(3), 221-230

NKASA, GA \& CHAPMAN, DW 2006: Sustaining community participation: What remains after the money ends? Review of Education, 52, 509 532 .

PADARATH,A; NTULI, A; SIBIYA, Z et al 2006: Community Participation in HIV Services, South African Health Review. Durban: Health Systems Trust

POLIT, DF \& BECK, CT 2004: Nursing Research: Principles and Methods, $7^{\text {th }}$ ed. Philadelphia: Lippincott Williams \& Wilkins

POLIT, DF; BECK, CT \& HUNGLER, BP 2001: Essentials of nursing research: methods, appraisals and utilization. $5^{\text {th }}$ edition. Philadelphia: JB Lippincott.

PORCHE, DJ 2004: Public \& Community Health Nursing Practice: A population- Based Approach. Thousand Oaks: SAGE Publications

REID, NJ 2000: Community Participation. USDA Rural Development. Accessed on $27 / 02 / 2009$ via http:// www.rurdev.usda.gov/rbs/ezec/Pubs/ commparticrept.pdf

REPUBLIC OF SOUTH AFRICA 2004: National Health Act (Act No. 61 of 2003), Government Gazette, 23, No. 26595

RIFKIN, SB 1990: Community partici- 
pation in maternal and child health/family planning programs: an analysis based on case study materials.., World Health Organization, 9-15.

STANHOPE, MS \& LANCASTER, J 2004: Community \& Public Health Nursing. St. Louis: CV Mosby. Please try to use the latest edition

VILJOEN, R; HEUNIS, C; JANSE VAN RENSBURG, E; VAN RENSBURG, D; ENGELBRECHT, M; FOURIE, A; STEYN, F \& MATEBESI, Z 2000: The National Primary Health Care Facilities Survey 2000. Durban: Health Systems Trust.

WHO see WORLD HEALTHORGANIZATION

WORLDHEALTHORGANIZATION 1978: Primary health care: report of the international conference on primary health care Alma Ata, USSR, 6-12 September 1978. Geneva: WHO.

WORLDHEALTHORGANIZATION 1988: From Alma Ata to the Year 2000: Reflections at the Midpoint. Geneva: WHO.

WORLDHEALTHORGANIZATION 2006: Community Involvement in Healthg. Addis Ababa

WRIGHT, J; PARRY, J \& MATHERS J 2005: Participation in health impact assessment: objectives, methods and core values. Bullet of the World Health Organization. 83(1), 58-63.

YIN, RK 2003: Case study research: design and methods. Newbury Park: Sage. 